\title{
PENGARUH PENGGUNAAN BALON SEBAGAI ALAT PERAGA PADA PEMBELAJARAN MATERI BENTUK MOLEKUL TERHADAP HASIL BELAJAR DAN AKTIVITAS SISWA KELAS X MIPA 1 DI SMA NEGERI 3 KOTABUMI TAHUN PELAJARAN 2018-2019
}

\author{
SITI MURSIDAH \\ Sitimursidahsman3ktb@gmail.com
}

\begin{abstract}
SMAN 3 KOTABUMI
Abstract: Low activity and student learning outcomes are the things that underlie this research. The purpose of this study was to increase the activity and learning outcomes of students in $X$ MIPA 1 SMAN 3 Kotabumi for the 2018-2019 academic year by using balloons as a medium for learning material in molecular form. This research was designed in the form of classroom action research and was carried out in class $x$ mipa 1 students of SMAN 3 Kotabumi in the 2018-2019 academic year. Data collection techniques using cognitive tests and student attitude questionnaires obtained from each cycle, the results were analyzed whether there was an increase in each cycle. Based on the results of this study, it shows that the use of balloons as teaching aids in learning material in molecular form can help improve learning outcomes of chemistry and student activities in class X MIPA 1. There is an increase in learning outcomes by $33 \%$ from cycle I to cycle II, while student activities based on questionnaires have increased in cycle II, students, easier to remember, easier to understand, happy with learning chemistry and active in learning.
\end{abstract}

Keywords: Balloon Props, Activities, Chemistry Learning Outcomes

Abstrak: Rendahnya aktivitas dan hasil belajar siswa menjadi hal yang melatari penelitian ini. Tujuan dari penelitian ini yaitu untuk meningkatkan aktivitas dan hasil belajar kimia siswa $X$ MIPA 1 SMAN 3 Kotabumi tahun pelajaran 2018-2019 dengan cara memanfaatkan balon sebagai media pembelajaran materi bentuk molekul. Penelitian ini dirancang dalam bentuk penelitian tindakan kelas dan dilaksanakan pada siswa kelas x mipa 1 SMAN 3 kotabumi tahun pelajaran 2018-2019. Teknik pengumpulan data dengan tes kognitif dan angket sikap siswa yang diperoleh dari tiap siklus, hasilnya dianalisis apakah terjadi peningkatan pada setiap siklus. Berdasarkan hasil penelitian ini menunjukkan pemanfaatan balon sebagai alat peraga pada pembelajaran materi bentuk molekul dapat membantu menaikan hasil belajar kimia dan aktivitassiswa kelas X MIPA 1. Terjadi kenaikan hasil belajar sebesar 33\% dari siklus I hingga siklus II, sedangkan aktifitas siswa berdasarkan angket mengalami kenaikan di siklus II, siswa, lebih mudah mengingat, lebih mudah memahami, senang dengan pembelajaran kimia dan aktif dalam pembelajaran.

Kata Kunci: Alat Peraga Balon, Aktivitas, Hasil Belajar Kimia

\section{PENDAHULUAN}

Keberhasilan suatu pembelajaran dilihat dari prestasi belajar yang di- hasilkan, dalam upaya peningkatan prestasi belajar siswa, selalu terkait dengan siswa dan guru.Untuk meningkatkan prestasi belajar siswa dibutuhkan guru-guru 
kreatif, guru yang mampu membuat pembelajaran dikelas menjadi menarik dan menyenangkan, guru yang selalui berusaha membantu siswa membangun pemahaman kognitifnya, guru yang berusaha menemukan model pembelajaran terbaik dikelasnya, guru yang berusaha memanfaatkan media pembelajran disekitarnya demi kelancaran transfer pengetahuan kepada siswanya

Untuk menciptakan suasana pembelajaran yang menarik dan menyenangkan guru dapat memanfaatkan berbagai media pembelajaran untuk menunjang transfer pengetahuan kepada siswanya terutama untuk materi pelajaran yang bersifat abstrak atau sulit ditampilkan, guru dapat membuat media pembelajaran yang bisa menghadirkan bentuk abstrak materi pelajaran, sehingga siswa akan lebih mudah memahaminya. Pelajaran kimia kelas X khususnya materi bentuk molekul, didalamnya ada banyak konsep bentuk molekul yang sulit untuk divisualkan kepada siswa, sehingga dalam menyerap pengetahuan dari guru terkadang siswa kesulitan memahami bentuk konkrit dari suatu bentuk molekul.

Alat peraga sebagai suatu media pembelajaran merupakan salah satu metode yang bisa diterapkan dalam pembelajaran materi abstrak. Dengan memanfaatkan alat peraga bentuk-bentuk yang sulit ditampilkan kepada siswa bisa dihadirkan kepada siswa berupa bentuk yang lebih sederhana dari bentuk aslinya. Salah satu media pembelajaran yang dapat digunakan yaitu balon, yaitu dengan cara menyusun balon sedemikian rupa sehingga bisa mewakili bentuk molekul.

Dengan memanfaatkan balon sebagai media dan alat peraga diharapkan dapat membantu siswa untuk memahami konsepkonsep abstrak pada materi bentuk molekul pelajaran kimia untuk kelas X MIPA 1 SMA Negeri 3 Kotabumi. Peneliti melakukan penelitian untuk mengetahui Pengaruh Menggunakan Media pembelajaran berupa Balon terhadap hasil belajar kimia materi bentuk molekul siswa X MIPA 1 tahun pelajaran 2018/2019 di SMA Negeri 3 Kotabumi

Rumusan permasalahan dalam penelitian ini yaitu: Apakah ada peningkatan aktivitas dan hasil belajar kimia materi bentuk molekul siswa X MIPA 1 tahun pelajaran 2018-2019 di SMA Negeri 3 Kotabumi dengan memanfaatkan balon sebagai alat peraga. Penelitian ini bertujuan untuk: mengetahui pengaruh pemanfaatan balon sebagai alat peraga kimia pada materi bentuk molekul ter-hadap hasil belajar dan aktivitas siswa X MIPA 1 tahun pelajaran 2018-2019 di SMA Negeri 3 Kotabumi

Belajar merupakan kegiatan yang berproses dan sebagai unsur yang utama dalam setiap kegiatan pembelajaran di semua lini jenjang pendidikaan. Di dalam 
belajar terjadi proses perubahaan tingkah laku menuju tahapan yang lebih baik (Sardiman, 2011). Hasil belajar merupakan hasil usaha siswa berupa pemahaman materi perubahan kebiasaan, keterampilan dan sikap. Hasil belajar dapat diukur dari sebuah tes, dimana siswa diberi kan soal untuk dijawabnya (Djamrah, 2011).

Arsyad (1997) mengatakan media pembelajaran adalah teknologi pembawa pesan yang dapat dimanfaatkan untuk keperluan pembelajaran. Media pembelajaran merupakan alat atau sumber daya untuk mentranfer atau mengkomunikasikan informasi materi pelajaran kepada siswa. Tujuan pemnafaat media pembelajaaran yaitu:

1. Memperbaiki keefektifan dan kualitas suatu kegiatan belajar.

2. Membantu guru menyelenggarakan suatu kegiatan belajar mengajar.

3. Membantu dalam mencapai tujuan suatu pembelajaran.

4. Menjadi alat evaluasi belajar secara mandiri.

5. Memotivasi guru untuk kreatif.

6. Mendukung proses transfer ilmu.

7. Menjembatani siswa memahami suatu pengetahuan tertentu.

Alat peraga adalah segala sesuatu yang dapat digunakan untuk menyatakan pesan merangsang pikiran, perasaan, perhatian dan kemauan siswa sehingga dapat mendorong proses belajar (Ali dalam Sundayana, 2014). Menurut Gagne alat peraga adalah suatu salak satu bagian sumber belajar dari lingkungan sekitar siswa yang membantu siswa dalam proses belajar. Alat peraga membantu memudahkan dan memperjelas siswa memahami konsep, prinsip, prosedur serta teori menjadi suatu informasi yang akan di serap siswa, diharapkan dengan adanya alat peraga proses transfer pengetahuan menjadi lebih menyenangkan dan meningkatkan keefektifan dan keefisienan belajar.

Penggunaan sarana belajar dalam suatu diskusi kelompok akan sangat membantu interaksi antar siswa menjadi lebih erat disebabkan hal yang dibahas akan lebih terfokus pada cara melakukan percobaan atau kegiatan yang dikerjakan berkenaan sarana atau alat peraga belajar.

Pada penelitian ini menggunakan alat peraga berupa balon yang bertujuan untuk membantu siswa dalam mem-visualkan bentuk molekul suatu senyawa secara 3 dimensi, dan membantu siswa merancang bentuk molekul sehingga pada akhirnya siswa lebih mudah memahami konsep bentuk molekul.

Cara kerja alat peraga menggunakan balon yaitu, bulatan balon yang berbeda warna berfungsi sebagai model dari atom , balon tersebut kemudian dirangkai menggunakan karet untuk penghubung. Balon 
tersebut akan digabung dan disusun sesuai bentuk molekul suatu senyawa. Dengan menggabungkan balon-balon dengan jumlah dan ukuran tertentu dapat menunjukkan bentuk rangkaian yang jelas sehingga dapat membantu memahami konsep bentuk molekul yang terdapat pada teori domain elektron.

\section{METODE PENELITIAN}

\section{Siswa $X$ MIPA 1 di SMAN 3} Kotabumi di dalam penelitian berperan sebagai subjek penelitian dengan jumlah 34 orang. Berikut ini merupakan gambaran tahapan setiap siklusnya.

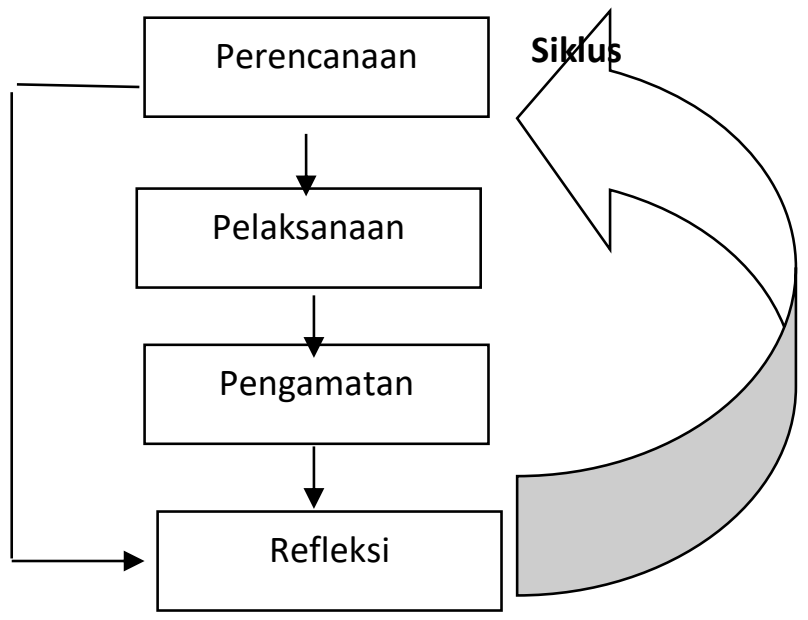

Bentuk penelitian ini sesuai dengan bentuk penelitian tindakan kelas, kegiatan dirancang untuk mengetahui pengaruh pemanfaatan balon sebagai alat peraga dalam pembelajaran materi bentuk molekul terhadap aktivitas dan hasil belajar kimia siswa. Di dalam penelitian ini tersusun dari beberapa siklus dan setiap siklus tersusun dari kegiatan perencanaa, dilanjutkan penelitian dan pengamatan dan diakhir siklus dilakukan Pada siklus I dilakukan penelitian pada materi teori VSEPR, sedangkan pada siklus II dibahas materi teori hibridisasi, dengan pembelajaran pada kedua materi tersebut diharapkan ada peningkatan hasil belajar kimia pada pokok bahasan bentuk molekul. Siklus terhenti jika keberhasilan telah tercapai.

Untuk mengumpulkan data penelitian digunakan instrument sebagai berikut:

1. Angket Kemampuan Afektif

Lembar Angket aktivitas siswa bertujuan untuk mendapatkan data tentang sikap dan aktivitas siswa selama prose belajar mengajar. Aspek yang dinilai pada lembar angket afektif yaitu aktivitas dalam pembelajaran.

2. Tes Kemampuan Kognitif

Tes dilaksanakan pada akhir kegiatan belajar mengajar. Hasil tes ini digunakan untuk mengukur hasil belajar Kimia dan tingkat ketuntasan belajar

\section{HASIL DAN PEMBAHASAN}

\section{Hasil}

Kegiatan penelitian terbagi menjadi 2 siklus dan masing-masing siklus meliputi tahapan perencanaan dilanjutkan pelaksanaan dan pengamatan serta ditutup 
dengan refleksi atau perbaikan. Pada siklus pertama para siswa masih kesulitan untuk merangkai dan menyusun balon untuk membentuk susunan sesuai bentuk molekul, tetapi hal ini bisa diatasi ketika siklus 2 berlangsung, para siswa sudah mampu menyelesaikan kegiatannnya dengan baik tanpa ada kesulitan yang berarti.

Ketika penelitian telah dilaksanakan data hasil penelitian diolah dan analisis dengan hasil berikut:

Tabel 1. Hasil belajar siswa

\begin{tabular}{|c|c|c|c|c|}
\hline \multirow{2}{*}{ siklus } & \multicolumn{2}{|c|}{ total } & \multicolumn{2}{c|}{$\%$} \\
\cline { 2 - 5 } & tuntas & $\begin{array}{c}\text { tidak } \\
\text { tuntas }\end{array}$ & tuntas & $\begin{array}{c}\text { tidak } \\
\text { tuntas }\end{array}$ \\
\hline 1 & 15 & 7 & 69 & 31 \\
\hline 2 & 20 & 2 & 91 & 9 \\
\hline
\end{tabular}

Sumber : Data hasil penelitian

Berdasarkan tabel tersebut dapat dilihat terjadi peningkatan kemampuan akademik siswa dalam mempelajari materi bentuk molekul

Pada tabel tersebut menunjukkan adanya kenaikan hasil belajar siswa pada siklus 1 jumlah siswa tuntas berjumlah 15 orang dengan persentase $69 \%$, jumlah ini mengalami kenaikan di siklus 2 menjadi 20 orang atau $91 \%$
Setelah melakukan pengolahan dan analisis data hasil lembar angket diperoleh data sebagai berikut:

Tabel 2. Tabel sikap siklus I

\begin{tabular}{|c|c|c|c|}
\hline \multirow{2}{*}{$\begin{array}{c}\text { Aspek sikap } \\
\text { siswa }\end{array}$} & \multicolumn{3}{|c|}{ Pilihan } \\
\cline { 2 - 4 } & selalu & Kadang-kadang & Tidak \\
\hline $\begin{array}{c}\text { Mengingat } \\
\text { materi }\end{array}$ & 4 & 14 & 4 \\
\hline $\begin{array}{c}\text { Memahami } \\
\text { materi }\end{array}$ & 6 & 14 & 2 \\
\hline $\begin{array}{c}\text { Senang } \\
\text { terhadap } \\
\text { pelajaran } \\
\text { kimia }\end{array}$ & 6 & 14 & 2 \\
\hline $\begin{array}{c}\text { Aktif dalam } \\
\text { pembelajaran }\end{array}$ & 3 & 14 & 5 \\
\hline
\end{tabular}

Tabel 3. Tabel sikap siklus 2

\begin{tabular}{|c|c|c|c|}
\hline \multirow{2}{*}{ Sikap siswa } & \multicolumn{3}{|c|}{ pilihan } \\
\cline { 2 - 4 } & selalu & $\begin{array}{c}\text { Kadang- } \\
\text { kadang }\end{array}$ & Tidak \\
\hline $\begin{array}{c}\text { Mengingat } \\
\text { materi }\end{array}$ & 15 & 7 & - \\
\hline $\begin{array}{c}\text { Memahami } \\
\text { materi }\end{array}$ & 18 & 4 & - \\
\hline $\begin{array}{c}\text { Senang } \\
\text { terhadap } \\
\text { kimia }\end{array}$ & 18 & 4 & - \\
\hline
\end{tabular}




\begin{tabular}{|c|c|c|c|}
\hline $\begin{array}{c}\text { Aktif dalam } \\
\text { pembelajaran }\end{array}$ & 17 & 5 & - \\
\hline
\end{tabular}

\section{Pembahasan}

Aktivitas siswa selama kegiatan pembelajaran membantu siswa untuk memahami konsep bentuk molekul, siswa berusaha untuk menyusun balon sedemikian rupa sehingga sesuai dengan bentuk molekul. Dengan melakukan kegiatan pembelajaran siswa lebih mudah untuk mengingat materi dan memahaminya, selain itu pembelajarn akan semakin menyenangkan bagi siswa.

Pada kegiatan di siklus I guru melaksanakan pembelajaran sesuai sintak pembelajaran di RPP, yaitu melakukan apersepsi, menjelaskan tentang teori VSEP dan mengelompokkan siswa untuk berlatih menyusun balon agar membentuk rangkaian molekul sesuai bentuk moleku di teori VSEPR.

Kegiatan berikutnya yaitu siswa berdiskusi dan bersama-sama menyusun rangkaian balon kemudian menggambarkan hasilnya di LKS dan mendiskusikan hasil gambar dengan konsep yang ada dimateri bentuk molekul.

Kendala yang terdapat pada siklus I yaitu siswa kesulitan untuk membentuk rangkaian balon seperti bentuk molekul, namun dengan bimbingan guru kendala tersebut perlahan bisa diatasi.
Setelah melakukan tes pada akhir siklus I diperoleh jumlah siswa tuntas dengan jumlah 20 orang atau $69 \%$ dari jumlah siswa keseluruhan. Jumlah ini masih belum mencapai target yang diharapakan. Untuk aktivitas belajar hasil lembar pengamatan menunjukkan selama kegiatan belajar telah muncul sikap mengingat materi, memahami materi, senang belajar kimia, aktif mengikuti pembelajaran.

Siklus kedua dilakukan dengan urutan kegiatan hampir sama dengan kegiatan disiklus satu, hanya berbeda pada materi yang dibahas yaitu tentang teori hibridisasi, pada siklus ke 2 kendala yang adadi siklus satu sudah tidak muncul, siswa tidak mengalami kesulitan saat merangkai balon, keaktifan siswa jungan semakin meningkat, hal ini terlihat bahwa siswa senang mengikuti kegiatan pem-belajaran, diskusi pun berjalan dengan baik dan pada akhirnya kesimpulan yang diambil diakhir pelajarn mudah untuk dirumuskan bersama-sama.

Pada siklus II juga dilakukan tes diakhir siklus, setelah dilakukan analisis dan pengolahan diperoleh data jumlah siswa tuntas belajar disiklus II dengan jumlah 20 orang atau $91 \%$, jika dibandingkan dengan siklus I maka mengalami kenaikan sebesar 22\%. Jumlah ketuntasan yang telah mencapai $91 \%$ ini telah melewati batas target yang di- 
harapkan, utuk sikap siswa selama pembelajaran juga mengalami kenaikan dibandingkan dengan siklus I.

\section{SIMPULAN}

Setelah melakukan penelitian maka PTK dengan judul "Pengaruh Penggunaan Balon Sebagai Media Pembelajaran Terhadap Peningkatan Pemahaman Siswa Kelas X MIPA 1 Tentang Bentuk Molekul

Di SMA Negeri 3 Kotabumi Tahun Pelajaran 2018-2019” dapat diambil kesimpulan sebagai berikut:

1. Ada peningkatan ketuntasan belajar pada pembelajaran menggunakan balon sebagai media pembelajaran siklus I sampai siklus II dengan ratarata kenaikannnya sebesar $22 \%$.

2. Aktivitas belajar siswa untuk indikator mengingat materi terjadi peningkatan

3. Aktivitas belajar indikator memahami materi mengalami kenaikan.

4. Aktivitas belajar untuk indikator senang belajar kimia terjadi kenaikan.

5. Aktivitas belajar indikator aktif dalam pembelajaran mengalami peningkatan

6. Hasil belajar mengajar kimia untuk materi bentuk molekul mengalami kenaikan dengan menggunakan balon sebagai media pembelajaran di kelas.

\section{DAFTAR PUSTAKA}

Arsyad, Azhar. (1997). Media Pengajaran. Jakarta: Raja Grafindo Persada

A.M. Sardiman. (2011). Interaksi dan Motivasi Belajar Mengajar. PT Rajagrafindo: Jakarta.

Djamarah, Syaiful Bahri. (2011). Psikologi Belajar. Jakarta: Rineka Cipta.

Sundayana, Rostina. (2014). Media dan Alat Peraga Dalam Pembelajaran Matematika. Bandung: Alfabeta 